\title{
Dizel Motorlarda EGR Gazlarının Soğutulmasında Harici Elektronik Kontrollü Soğutma Stratejisinin BSFC ve NO $_{x}$ Emisyonlarına Etkisi
}

\author{
Halil İbrahim AKOLAȘ ${ }^{1 *}$, Alirıza KALELI' ${ }^{2}$, Kadir BAKIRCI ${ }^{3}$ \\ ${ }^{1}$ Bitlis Eren Üniversitesi, Teknik Bilimler MYO, Bitlis \\ ${ }^{2}$ Samsun Üniversitesi, Elektrik-Elektronik Mühendisliği Bölümü, Samsun \\ ${ }^{3}$ Atatürk Üniversitesi, Makine Mühendisliği Bölümü̈, Erzurum \\ (ORCID:0000-0002-3153-8044) (ORCID:0000-0002-3234-5922) (ORCID:0000-0001-5447-4955)
}

\begin{abstract}
$\ddot{O} z$
Dizel motorlar insan ve çevre sağlığı açısından zararları etkileri olan azot oksit $\left(\mathrm{NO}_{\mathrm{x}}\right)$ ve partikül madde (PM) yayarlar. Dizel motorlarda $\mathrm{NO}_{\mathrm{x}}$ salınımını düşürmek için kullanılan etkin ve yerleşik sistemlerden biri egzoz gaz resirkülasyon (EGR) sistemidir. Bu deneysel çalışmada, EGR sisteminin $\mathrm{NO}_{\mathrm{x}}$ ve fren özgül yakıt tüketimi (BSFC) üzerine olan etkileri araştııılmıştır. Çalışmada emme manifolduna giren EGR gaz sıcaklıkları ile EGR oranları birlikte ele alınmıştır. Deneyler kararlı durum çalı̧̧ma koşullarında, 1700 d/d, 2000 d/d'da, \%5, \%10, \%15 EGR oranlarında, yüklü ve yüksüz koşullarda yapılmıştır. EGR gaz sıcaklıklarının etkin bir şekilde kontrol edilebilmesi için EGR soğutucusu, motor ana soğutma sisteminden ayrılmıştır. Radyatör, elektrikli su pompası, elektrikli fan, sıcaklık sensörleri ve kontrolcüden oluşan harici elektronik kontrollü bir soğutma sistemi tasarlanmıştır. Gerçekleştirilen deneyler sonucunda eş zamanlı olarak, \%15 EGR ve $75^{\circ} \mathrm{C}$ de optimum $\mathrm{NO}_{\mathrm{x}}$ ve $\mathrm{BSFC}$ değerlerinin elde edildiği görülmüştür.
\end{abstract}

Anahtar kelimeler: Dizel motor, $\mathrm{NO}_{\mathrm{x}}$, EGR soğutucu, BSFC.

\section{The Effect of External Electronically Controlled Cooling Strategy in Diesel Engines on BSFC and NO $_{x}$ Emissions in EGR Gas Cooling}

\begin{abstract}
Diesel engines emit nitrogen oxide $\left(\mathrm{NO}_{\mathrm{x}}\right)$ and particulate matter $(\mathrm{PM})$, which have harmful effects on human and environmental health. Exhaust gas recirculation (EGR) system is one of the efficient and built-in systems used to reduce $\mathrm{NO}_{\mathrm{x}}$ emissions in diesel engines. In this experimental study, the effects of EGR system on $\mathrm{NO}_{\mathrm{x}}$ and brake specific fuel consumption (BSFC) were investigated. In this study, EGR gas temperatures entering the intake manifold and EGR ratios are discussed together. The experiments were carried out under steady-state operating conditions, at $1700 \mathrm{rpm}, 2000 \mathrm{rpm}, 5 \%, 10 \%, 15 \%$ EGR ratio, under load and no load conditions. The EGR cooler is disconnected from the engine main cooling system to effectively control EGR gas temperatures. An external electronically controlled cooling system consisting of radiator, electric water pump, electric fan, temperature sensors and controller is designed. As a result of the experiments carried out, it was observed that optimum $\mathrm{NO}_{\mathrm{x}}$ and BSFC values were obtained simultaneously at $15 \%$ EGR and $75^{\circ} \mathrm{C}$.
\end{abstract}

Keywords: Diesel engine, $\mathrm{NO}_{\mathrm{x}}$, EGR cooler, BSFC.

\section{Giriş}

Modern dünyamızda hızla artan nüfus, gelişen bilim ve teknoloji içten yanmalı motorlu taşıtların kullanımı giderek artırmaktadır. Özellikle dizel motorlu taşıtların düşük yakıt tüketimi ve yüksek verimlerinden dolayı karayollarında ulaşım, taşıma ve yardımcı güç gereksinimlerini karşılama amaçlı kullanımları giderek artmaktadır. Motorlu taşıtların yoğun kullanımı atmosferde sera gazı olarak bilinen karbon dioksit $\left(\mathrm{CO}_{2}\right)$ miktarındaki artışa ve bu artışın sonucu olarak "Küresel Isınma" ve "İklim

\footnotetext{
"Sorumlu yazar: hakolas@beu.edu.tr

Geliş Tarihi: 08.09.2019, Kabul Tarihi: 06.05.2020
} 
Değişikliğii" gibi canlı yaşamı tehdit eden çok ciddi çevre sorunlarına sebep olmaktadır [1]. Motorlu taşıt emisyon düzenlemelerinin giderek katılaşmasına paralel olarak, dizel motorların birincil emisyonları olan azot oksit $\left(\mathrm{NO}_{\mathrm{x}}\right)$ ve partikül madde $(\mathrm{PM})$ gibi zararlı kirleticilerin azaltılması için uluslararası bir çaba gösterilmektedir [2]. Dizel motor yakıtının kimyasal yapısının sağlamış olduğu yüksek sıkıştırma oranı nedeniyle fakir karışımla çalışırlar [3]. Yüksek sıkıştırma oranı sayesinde kendiliğinden tutuşma sıcaklığına ulaşırlar ve bu nedenle benzinli motorlara kıyasla daha yüksek bir termik verime sahiptirler $[4,5]$. Dizel motorlar atmosfere, benzin motorlara oranla daha az hidrokarbon (HC) ve karbon monoksit (CO) yaymalarına karşılık daha fazla $\mathrm{NO}_{\mathrm{x}}$ ve $\mathrm{PM}$ yayarlar. Dolayısı ile bu motorlarda egzoz emisyon değerlerinin azaltılması her zaman başarılması gereken bir hedef olarak görülmüştür [6]. Taşıt emisyon değerleri, çevresel sorunların azaltılması ve doğal yaşamın korunması adına yasalarla giderek kısıtlanmaktadır.

Benzinli ve dizel motorlar farklı yanma stratejileri altında çalıştıklarından dolayı her iki motor farklı emisyon seviyeleri yayar ve bu motorlarda farklı emisyon azaltma yöntemleri kullanılır. Sıkıştırma ateşlemeli motorların egzoz gazındaki $\mathrm{NO}_{\mathrm{x}}$ miktarını azaltmaya yönelik silindir içi yanma stratejileri olan; pilot enjeksiyon, egzoz gaz resirkülasyonu (EGR), su buharı yöntemlerinin yanı sıra yanma sonrası egzoz hattında son işlem olarak; seçici katalitik indirgeme (SCR), dizel partikül filtresi (DPF), dizel oksidasyon katalizörü (DOC), fakir $\mathrm{NO}_{\mathrm{x}}$ tuzağı (LNT)) ve son olarak yakıtla bağlantılı emisyonları azaltma stratejileri veya bunların değişen kombinasyonları uygulanmaktadır. Bahsi geçen bu yöntemlerden EGR, dizel motorlarda $\mathrm{NO}_{\mathrm{x}}$ emisyonlarını azaltmada maliyeti ve faydası göz önüne alındığında etkili, yerleşik yöntemlerin başında gelmektedir $[2,7,8]$. Bu yöntemde $\mathrm{NO}_{\mathrm{x}}$ emisyonlarını azaltmak adına egzoz gazı tekrardan emme manifolduna yönlendirilerek temiz hava ile birlikte yanma işlemine tabi tutulur. EGR gazlarının çoğunluğu $\mathrm{CO}_{2}$ ve su buharından $\left(\mathrm{H}_{2} \mathrm{O}\right)$ oluşması, ateşleme gecikmesinde bir artışa ve yanma başlangıcında bir uzamaya neden olur. EGR'nin dizel motorlarda uygulanması, emme dolgusunun hem bileşenlerinin $\left(\mathrm{CO}_{2} \mathrm{ve}_{2} \mathrm{O}\right.$ ilavesi ile) hem de fiziksel koşullarının (sıcaklık, yoğunluk) değişimine neden olur. Bu değişiklikler yanma işlemini ve sonuç olarak egzoz emisyonlarını etkiler [9]. Pek çok araştırma, dizel motorlarda EGR'nin $\mathrm{NO}_{\mathrm{x}}$ emisyonlarını azaltmada oldukça etkili olduğunu göstermiştir. Bununla birlikte, yakıt tüketimi ve diğer emisyonları da artırmaktadır. Ancak bu artı̧̧ enjeksiyon parametrelerini optimize ederek, gaz hareketini iyileştirerek ve gerekirse DPF eklenerek kabul edilebilir seviyelere düşürülebilir [7]. EGR sistemi sayesinde silindir içi sıcaklığın düşürülmesi motor servis ömrünün uzamasına katkı sağlamaktadır. Ayrıca EGR sayesinde dizel motorlar daha az miktarda toksik madde oluştururlar [10]. Bu olumlu taraflarının aksine fazla miktarda EGR, emme dolgusunun sıcaklığını, duman oluşumunu ve partikül madde miktarını artırmaktadır [11]. Aynı şekilde egzoz gazında bulunan sülfürik tuzlar, piston segmanı ve silindir gömlekleri gibi mekanik parçaların aşınmasına ve çürümesine neden olabilmektedir [5, 12].

EGR sistemine sahip motorlarda sıcak egzoz gazları, emme dolgusu sıcaklığını artırır. Bu durum hacimsel verimin kötüleşmesine ve silindir içi yanma sürecinin bozulmasına sebep olur. Bu süreçte yanma odası içerisindeki bu bozulmanın $\mathrm{NO}_{\mathrm{x}}$ oluşumundaki negatif etkilerini azaltmak için egzoz gazlarının emme dolgusu ile karışmadan önce soğutulması gerekir. EGR gazlarının soğutulması genellikle motor soğutma sistemi ile bağlantı olan bir 1sı değiştiriciden geçirilerek soğutulur.

Klasik motor soğutma sisteminde devir daim pompasının, motor devir sayısı ile bağlantılı olması, taşıt motorunda enerji kayıplarına neden olmakta ve EGR gazların sıcaklığ değerlerden uzaklaşmaktadır. Bu nedenle klasik motor soğutma sistemleri bu sicaklık ayarlamasına imkân tanımaz. Dolayısıyla harici ve kontrol edilebilir bir soğutma sistemi sayesinde EGR soğutucudan çıkan egzoz gazlarının sıcaklığı istenen seviyelerde tutulabilir.

$\mathrm{Bu}$ çalışmada motor ana soğutma sisteminden bağımsız, motor hızına ve termostatik valfe bağlı olmayan, gelişmiş bir termal yönetim sistemi ile kontrolü sağlayan bir elektronik kontrollü harici soğutma sistemi devreye entegre edilmiştir. Bu sistem ayrı bir radyatör, elektrikli su pompası, elektrikli fan, sicaklık sensörü ve elektronik kontrolcüden ibarettir. Bu yöntem sayesinde daha hassas sicaklık ayarlama noktaları tespit edilebilir ve daha optimum $\mathrm{NO}_{x}$ emisyon oluşumlarına imkân tanınabilir.

\section{2. $\mathrm{NO}_{\mathrm{x}}$ Oluşum Mekanizması}

$\mathrm{NO}_{2}$, etkin bir kokuya sahip olup koyu renkli bir gazdır. Düşük dozlarda bile akciğere, dokulara ve mukoza zarına zarar verir. Kimyasal bir yapısı olan bu gazın işletme ortamında etkisiz olduğu ve müsaade edilen azami konsantrasyon değeri $9 \mathrm{mg} / \mathrm{m} 3$ 'tür [13]. $\mathrm{NO}_{\mathrm{x}}$ silindir içerisinde sıcaklığın yüksek 
olduğu bölgelerde, özellikle kıvılcımın (alevin) oluştuğu bölge gerisinde meydana gelen bir kimyasal reaksiyon ürünleridir. Dizel yakıtın sıkıştırma basıncı etkisi altında hava ile yanmaya tabi tutulması neticesinde aşağıdaki kimyasal denklemdeki ürünler atmosfere salınır.

$$
\mathrm{C}_{17} \mathrm{H}_{34}+25,5 \lambda\left(\mathrm{O}_{2}+3,76 \mathrm{~N}_{2}\right) \rightarrow \mathrm{CO}_{2}, \mathrm{CO}, \mathrm{CH}_{4}, \mathrm{H} . \mathrm{CHO}, \mathrm{C}, \mathrm{SO}_{2}, \mathrm{SO}_{3}, \mathrm{H}_{2} \mathrm{O}, \mathbf{N O}, \mathbf{N O}_{2}, \mathbf{N}_{2}
$$

Yukarıda bahsedildiği üzere yanma odası içerisindeki bu kimyasal reaksiyon ile oluşan bozulma ve $\mathrm{NO}_{\mathrm{x}}$ emisyonları, genişletilmiş Zeldovich mekanizması ile açıklanabilir [13]. $\mathrm{NO}_{\mathrm{x}}$ oluşumunu başlatan ana reaksiyon iyonları aşağıdaki gibidir [10].

$$
\begin{aligned}
& \mathrm{O}+\mathrm{N}_{2}=\mathrm{NO}+\mathrm{N} \\
& \mathrm{N}+\mathrm{O}_{2}=\mathrm{NO}+\mathrm{O} \\
& \mathrm{N}+\mathrm{OH}=\mathrm{NO}+\mathrm{H}
\end{aligned}
$$

\subsection{Egzoz Gaz Resirkülasyon (EGR) Sistemi}

Modern dizel motorların imalat-bakım masraflarındaki düşüş ve motor verimlerinin fazla olması sebebiyle dizel motorların kullanımı benzinli motorlara göre daha çok tercih sebebi olmuştur. Fakat dizel motordan kaynaklı $\mathrm{NO}_{x}$ ve PM emisyonlarının atmosfere salınımları, benzinli motorlara oranla daha yüksektir. Bu yüzden, motorun verimliliğini bozmadan emisyonları düşüren sistemlere ihtiyaç vardır. Bu sistemlerden biri olan Egzoz Gaz Resirkülasyon (EGR) sistemi, $\mathrm{NO}_{\mathrm{x}}$ emisyonlarını azaltmak için etkin ve geçerli bir sistemdir. EGR sisteminde arzu edilen oranda egzoz gazı, çevrim esnasında tekrardan emme manifolduna gönderilir. Bu yöntemin uygulanması dizel motorun yanma sürecini 1sıl, kimyasal ve seyreltme olarak farklı şekillerde etkiler [14]. Egzoz gazlarının büyük kısmı nem $\left(\mathrm{H}_{2} \mathrm{O}\right)$ ve karbondioksit den $\left(\mathrm{CO}_{2}\right)$ meydana geldiği için emme dolgusu içerisindeki $\mathrm{O}_{2}$ miktarı, EGR gaz ilavesi ile düşürülür. Oksijen miktarındaki bu düşüş silindir içerisinde yanma sıcaklığının düşmesine ve bunun sonucu olarak $\mathrm{NO}_{\mathrm{x}}$ salınımında bir azalmaya neden olur. Egzoz gazlarının bir diğer etkisi ise, egzoz gazlarının havaya nispeten daha fazla özgül ssıya sahip olmalarıdır. $\mathrm{O}_{2}$ ile reaksiyona giren azot moleküllerinin azalması nedeniyle yanma sıcaklığındaki düşüş $\mathrm{NO}_{\mathrm{x}}$ oluşumunda bir azalmaya neden olurken EGR sistemine sahip olmayan bir motora göre daha fazla duman (PM ve yanmamış HC) üretimine sebep olmaktadır [15]. EGR'li dizel motorlar üzerinde $\mathrm{NO}_{\mathrm{x}}$ salınımını azaltmak adına kararlı durum çalışma koşullarında pek çok deneysel çalışma gerçekleştirilmiş ve bu çalışmalar EGR uygulamasının $\mathrm{NO}_{\mathrm{x}}$ salınımında yaklaşık \%50 azalma, PM miktarında ise \%100 artışa sebep olduğu görülmüş̧ür [16, 17]. Şekil 1'de dizel motorlarda en sık kullanılan EGR sistem türleri görülmektedir.
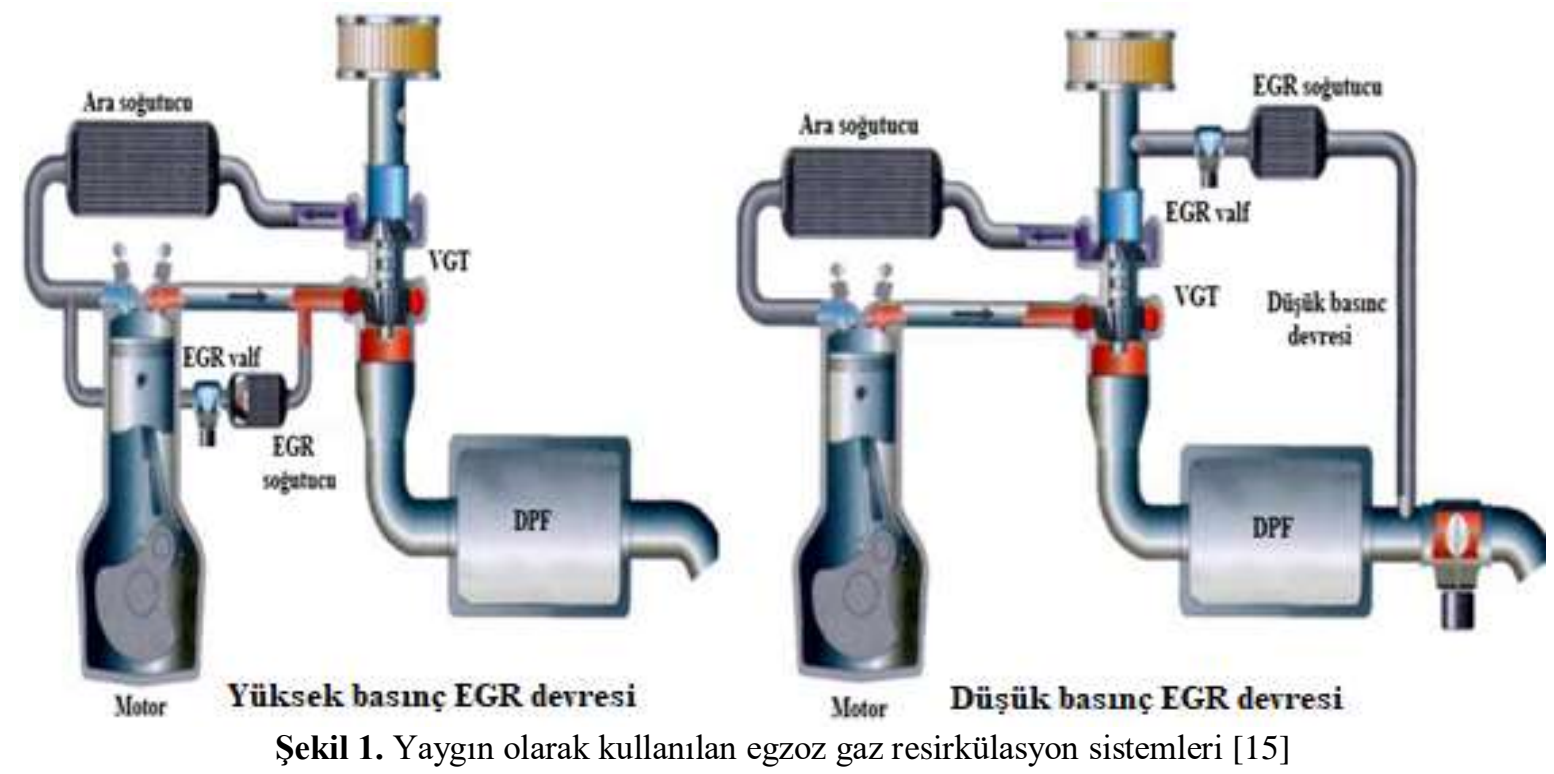

EGR sisteminin kullanılması; kurum emisyonları (PM emisyonlarının önemli bir parçası olan ve yanma odası sıcaklığına bağlı olan yanmamış HC) açısından EGR'siz motorlardan daha çok 
hidrokarbon (\%20-30) ve daha düşük oranda egzoz gazı yayarlar. Çünkü arzu edilen miktarda egzoz gazının (EGR oranı miktarınca) tekrardan emme manifolduna yönlendirilmesinden kaynaklanır. Emme dolgusu sıcaklığındaki yükselme, daha kısa tutuşma gecikmesine sebep olur ve ssıl verimi artırabilir [18]. EGR gaz miktarındaki artış emme havası sıcaklığının artmasına sebep olurken oksijen konsantrasyonlarında bir düşüşe (Termal kısılma) sebep olur. Bu durum, PM artışına neden olur [11]. EGR gazları direk silindir içine gönderilirse sıcak EGR, bir 1sı değiştiricide soğutularak silindirlere gönderiliyorsa soğutulmuş EGR olarak adlandırılırlar [5].

EGR uygulaması $\mathrm{NO}_{\mathrm{x}}$ emisyonlarını azaltırken PM artışına neden olur. Bu durum EGR'li motorların kronik sorunlardan biridir. Dolayısı ile motor performansında kayıp olmadan $\mathrm{NO}_{\mathrm{x}}$ ile PM arasında bir denge olması gerekir. EGR gazları, emme dolgusu sıcaklığında artışa sebep olması; hacimsel verimi, yanma sürecini ve $\mathrm{NO}_{\mathrm{x}}$ oluşumunu olumsuz yönde etkileyeceğinden, EGR gazları emme dolgusu ile karışmadan önce soğutulmalıdır. Emme dolgusu sıcaklığındaki azalma yakıt tasarrufunu korurken optimum $\mathrm{NO}_{\mathrm{x}}$ elde etmeye büyük katk1 sağlar. Mevcut dizel motorlar; EGR soğutucu etkinliğini optimum seviyelere ayarlanmasına izin vermez. Çünkü klasik EGR sisteminde egzoz gazları, motor ana soğutma sistemi tarafından soğutulur. Bu durum soğutucu akışkanın motor hızına ve termostatik valfe bağlı olarak çalıştığından soğutucu akışkan debisinin kontrolüne izin vermez [19].

\section{Materyal ve Metot}

\subsection{EGR Oranı ve Hesaplanması}

Literatürde emme dolgusuyla karışacak EGR oranı hesaplamalarında, devir daim edilen egzoz gazının kütlesinin, silindire dolan toplam emme dolgusunun kütlesine oranıyla hesaplanır Eş. (1). En yaygın olarak kütle bazlı ve gaz konsantrasyon bazlı olmak üzere iki matematiksel tanım kullanılmaktadır [20]. $\mathrm{Bu}$ çalışmada gaz konsantrasyon bazlı yaklaşım tercih edilmiştir.

(\%) $E G R=\frac{M_{E G R}}{M_{i}} \times 100$

Burada (\%) $E G R$ oranı, $M_{E G R}$ emme dolgusuna yönlendirilen EGR gazlarının kütlesini, $M_{i}$ ise toplam silindire giren emme dolgusunun kütlesini ifade etmektedir. Emme dolgusu, dikkate alınmayacak miktarda $\mathrm{CO}_{2}$ içerirken, egzoz manifoldunda ise kayda değer oranda $\mathrm{CO}_{2}$ bulunur. Bundan dolayı, egzoz $\left(\mathrm{CO}_{2 \_ \text {egzoz }}\right)$ ve emme manifolduna yönlendirilen egzoz gazındaki karbondioksit $\left(\mathrm{CO}_{2 E G R}\right)$ konsantrasyonlarının ölçülmesi, EGR oranının hesaplanmasında tercih edilen bir yoldur [21]. Emme ve egzoz manifoldlarındaki karbondioksit miktarlarını ölçmek için NonDispersive InfraRed (NDIR) sensörler kullanılır ve (\%) EGR oranı Eş. (2) deki gibi hesaplamışlardır [22-24].

(\%) $E G R=\left[\frac{\mathrm{CO}_{2_{E G R}}-\mathrm{CO}_{2} \text { atm }}{\mathrm{CO}_{2_{\text {egzoz }}}-\mathrm{CO}_{2_{\text {atm }}}}\right] * 100$

Geleneksel olarak evrensel egzoz gazı oksijen sensörleri (UEGO) genellikle hava-yakıt oranı (AFR) ve hava fazlalık katsayısı $(\lambda)$ ölçümleri için motorlarda kullanılmaktadır. UEGO sensörleri 80 ms gbi hızlı tepki süresine sahip olmaları sebebiyle dizel motorlarda da kullanılmaktadır. Bu sensörler ile (\%) EGR oranının hesaplanması Eş. (3) de verilmiştir [25]. Bu deneysel çalışmada EGR oranının hesaplanmasında emme ve egzoz manifoldlarında iki adet Bosch marka LSU 4.9 geniş band UEGO sensörleri kullanılmıştır.

$E G R=\frac{O_{2_{a t m}}-O_{2_{e m m e}}}{O_{2_{a t m}}-O_{2_{\text {egzoz }}}}$

$O_{2 \_ \text {emme }}$, emme dolgusundaki, $O_{2 \_e g z o z}$ egzozdaki ve $O_{2 \_a t m}$ ise ortamdaki oksijen miktarlarını temsil etmektedir. UEGO sensörleri aracılığı ile oksijen miktarlarının hesaplanmasında Bosch'un teknik dokümanlarından alınan Eş. (4) deki formül ile hesaplanmıştır. 
$x O_{2}=\frac{3 *(\lambda-1)}{(1+3 * K * \lambda)}$

Burada $\mathrm{xO}_{2}$ oksijen yüzdesini, $\lambda$ lambda, $\mathrm{K}$ ise kalibrasyon katsayısı olup serbest hava oksijen konsantrasyonuna bağlıdır ve 4.76 ya da 4.77 olarak hesaplanmaktadır. Geniş bandlı bir sensör, fazla oksijen moleküllerini etkisizleştirmek için düşük bir pompa akımı ile sağlanan küçük bir gaz ölçüm haznesine (difüzyon odası) sahiptir. Bu şekilde, pompa akımı örneklenen gazdaki doğrudan oksijen yüzdesidir. UEGO sensörünün çıkışı (pompa akım voltajı) LabVIEW modülüne bağlanır. Ölçülen pompa voltajı Eş. (5) kullanılarak pompa akımına dönüştürülür ve ayrıca Bosch sensör el kitabından arama tablosu kullanılarak (\%) oksijene dönüştürülür.

$I_{p}=\frac{V_{A}-1.5}{496}$

Burada $I_{p}, A$ 'da ki pompa akımını, $V_{A}$ ise pompa voltajını ifade etmektedir. Okunan Oksijen konsantrasyonları eş zamanlı olarak LabVIEW programında yukarıda verilen Eş. (3) ile EGR oranı hesaplanmıştır.

\subsection{Deneysel Kurulum}

Bu deneysel çalışmada; dört zamanlı Ford marka 92 kW, 2.2 TDCİ dizel motoru kullanılmış olup, Tablo 1 'de teknik özellikleri verilmiştir. Ayrıca egzoz emisyon ölçümünde kullanılan Bosch marka BEA 270 emisyon cihazının ölçüm aralığı ve hassasiyeti Tablo 2'de verilmiştir. $\mathrm{NO}_{\mathrm{x}}$ emisyon ölçümlerinde National Instruments firmasına ait NI 9755 Powertrain Controls CompactRIO $\mathrm{NO}_{\mathrm{x}}$ sensör modülü kullanılmıştır. Bunun dışında, yakıt tüketimi ölçümünde Kistler DFL3X-5 bar yakıt akış ölçer, egzoz gazlarının ve soğutucu akışkanın; EGR soğutucu eşanjör giriş ve çıkışındaki sıcaklık değişimleri K tipi termokupllar ile ölçülmüştür. Motor soğutma suyu sıcaklığı, motor devri, yakıt basıncı, emme manifold basınc1, emme havası sıcaklığı ve hava akış miktarı (MAF) ölçümleri on-board diagnostics (OBD II) üzerinden okunarak veri toplama ve kontrol ünitesine iletilmiştir. Tüm ölçümler ve kontrol sinyalleri bilgisayarda LabVIEW ortamında hazırlanan kodlarla gerçekleştirilmiş ve eş zamanlı alan programlanabilir kapı dizisi (FPGA) şasisi üzerinden koşturulmuştur. Deneysel çalışmalar Erzurum Atatürk Üniversitesi Bilimsel Araştırma Projeleri (BAP) Koordinasyon biriminin destekleriyle, Atatürk Üniversitesi makine mühendisliği bölümü enerji laboratuvarı şartlarında gerçekleştirilmiştir.

Tablo 1. Bosch BEA 270 emisyon cihazı ile ölçülen gazlar, ölçüm aralığı ve hassasiyeti

\begin{tabular}{|l|l|l|}
\hline Bileşenler & Ölçüm Aralığ1 & Hassasiyet \\
\hline CO & $0,000-10,00 \%$ Hacim & $0,001 \%$ Hacim \\
\hline CO2 & $0,00-18,00 \%$ Hacim & $0,01 \%$ Hacim \\
\hline HC & $0-9,999$ ppm Hacim & 1 ppm Hacim \\
\hline O2 & $0,00-22,00 \%$ Hacim & $0,01 \%$ Hacim \\
\hline Lambda & $0,500-9,999$ & 0,001 \\
\hline NO & $0-5000$ ppm Hacim & $\leq 1$ ppm Hacim \\
\hline
\end{tabular}

Tablo 2. Deney motorunun teknik özellikleri

\begin{tabular}{|c|c|}
\hline Motor & FORD PUMA \\
\hline Silindir sayısı & 4 \\
\hline Turboşarjlı & EGR (High pressure) \\
\hline Maksimum güç/devir $(\mathrm{kW} /(\mathrm{d} / \mathrm{d}))$ & $92 / 3500$ \\
\hline Maksimum tork/devir $(\mathrm{Nm} /(\mathrm{d} / \mathrm{d}))$ & $350 /(1450-2000)$ \\
\hline Toplam silindir hacmi & $2198.1 \mathrm{cc}$ \\
\hline Kurs boyu & $94.6 \mathrm{~mm}$ \\
\hline Piston çapı & $86 \mathrm{~mm}$ \\
\hline Sikş̧tırma oranı & $15.5: 1$ \\
\hline
\end{tabular}

Gerçek motor deney düzeneği Şekil 2'de, deneysel düzeneğin şematik görüntüsü ise Şekil 3'de görülmektedir. 


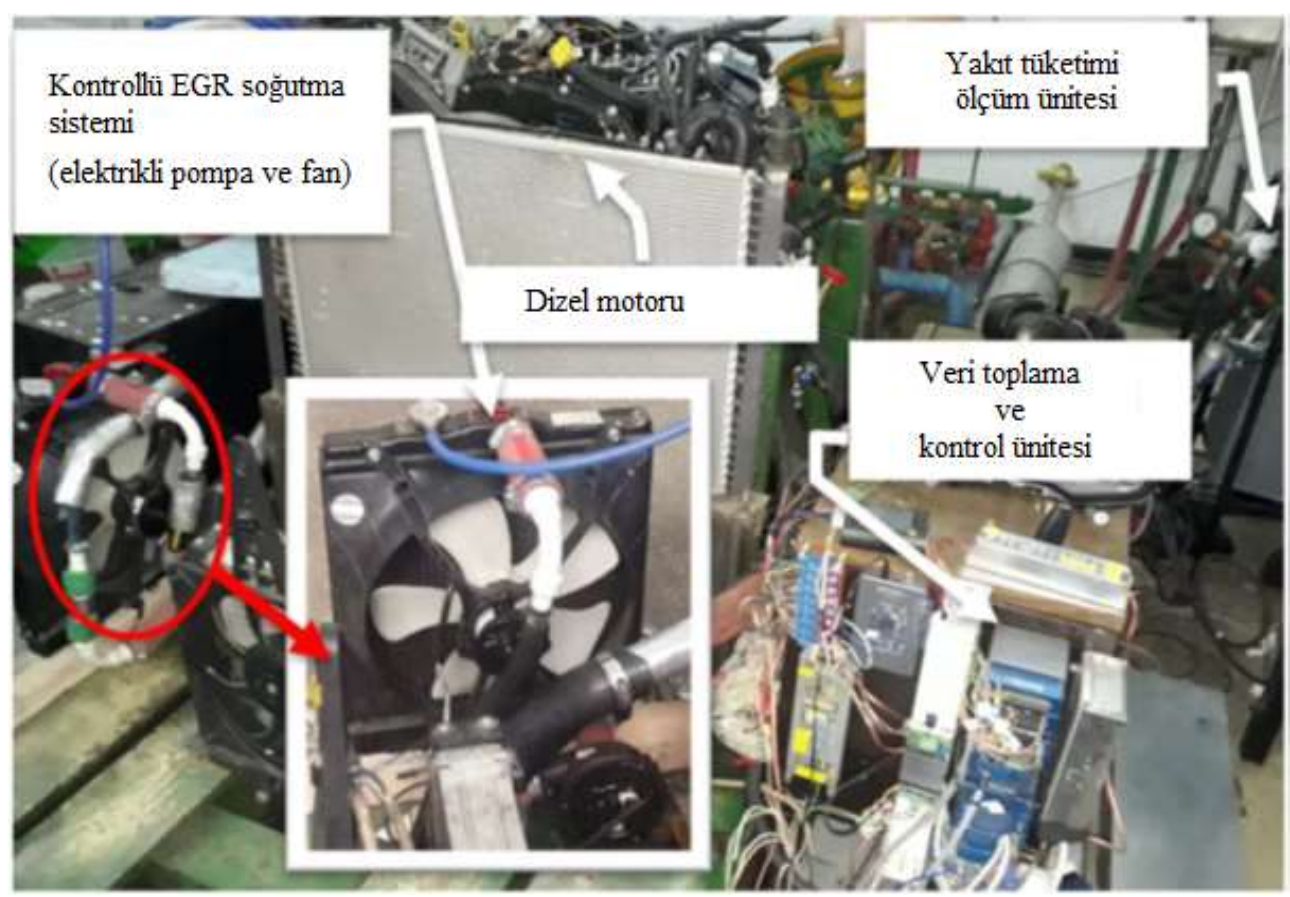

Şekil 2. Gerçek motor deney düzeneği

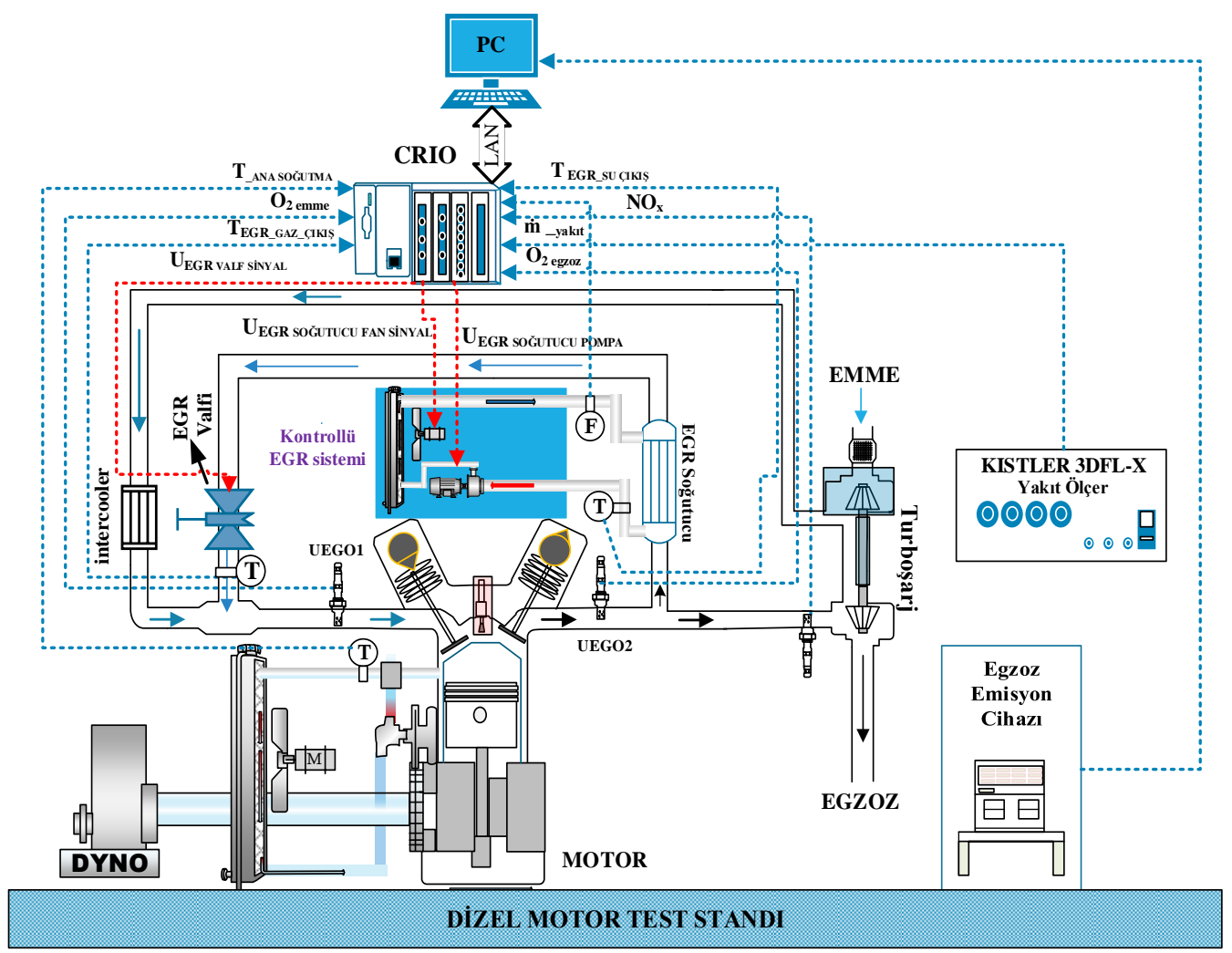

Şekil 3. Gerçek motor deney düzeneğinin şematik görünümü

\subsection{Harici Elektronik Kontrollü EGR Soğutma Sistemi}

Motor yükü, EGR verimliliğini etkileyen faktörlerden biridir. Yüksek yüklerde, soğutulmuş EGR istenir. Çünkü EGR kütlesini arttırmak giriş dolgusu sıcaklığını daha da düşürür ve EGR gaz yoğunluğunu arttırır. Bununla birlikte, düşük yüklerde, daha yüksek bir EGR oranı kararsız yanmaya neden olabilir. Fakat daha yüksek EGR giriş sıcaklığı yanmayı dengeleyeceğinden, düşük yüklerde daha yüksek EGR sıcaklığı istenir. EGR sisteminde EGR gaz sıcaklıklarını optimum $\mathrm{NO}_{\mathrm{x}}$ emisyonu elde 
edebilmek için deneysel düzenekte EGR gazlarının soğutulması, motor ana soğutma sisteminden ayrılmıştır. Klasik bir motor soğutma sistemi, mekanik su pompası, soğutma fanı, radyatör ve mum tipi termostat olmak üzere dört ana bileşene sahiptir. Bu bileşenler çeşitli motor sürüş koşullarından bağımsız değildir [26].

Klasik motor soğutma sistemlerinin verimliliği motorun çalışma devrine bağlı olduklarından mekanik su pompası, termostat ve fan tepkilerinde bir takım zorluklarla karşılaşılmaktadır. $\mathrm{Bu}$ nedenlerden dolayı, termal yönetim sisteminin esnek bir şekilde kontrol edilmesi, mevcut soğutma teknolojisi ile büyük zorluklar yaşamaktadır. Teknolojik alandaki gelişmeler sayesinde elektronik kontrollü pompalar ve aktüatörler önemli ölçüde geliştirilmiştir [27]. Bu nedenle, klasik soğutma sistemlerindeki aksaklıklar, mekanik olarak tahrik edilen sistemin elektronik olarak kontrol edilebilir olanlarıyla değiştirilmesi sayesinde daha verimli hale gelebilir. Bu deneysel çalışmada EGR'nin soğutulması için, harici kapalı döngüde çalışan elektronik kontrollü bir soğutma sistemi tasarlanmıştır. $\mathrm{Bu}$ sistemde kontrol edilen çıkış değişkeninin ölçülmesi $\left(\mathrm{NO}_{\mathrm{x}}\right)$ geri beslenerek istenilen EGR gaz giriş sıcaklığı ile karşılaştırıldığı kapalı devre kontrol sistemidir. Sistemin çıkışı, istenilen çıkış değerini karşllayacak biçimde giriş büyüklüğü ile ayarlanabilen klasik oransal (Proportional) integral (Integral) (PI) kontrol yapısına sahiptir. Tasarlanan bu sistem, EGR gazının sıcaklı̆̆ını kontrol edebilmek için 12 DC volt elektrik motorlu su pompası (EWP), 12 DC volt firçasız elektrik motorlu fan, radyatör, NTC tip sıcaklık sensörü ve elektronik kontrolcüden oluşmaktadır (bk. Şekil 4). Elektronik kontrolcü sistem, elektrik motorlu su pompasını, hedeflenen EGR gaz sıcaklığını korumak için tam olarak doğru akış hızında çalıştıracak gerilimle besleyen bir mikroişlemciye sahiptir. Optimum $\mathrm{NO}_{\mathrm{x}}$ salınımı ve en uygun EGR gaz çıkış sıcaklığında tutabilmek için sistem dışardan ayarlanabilmektedir.
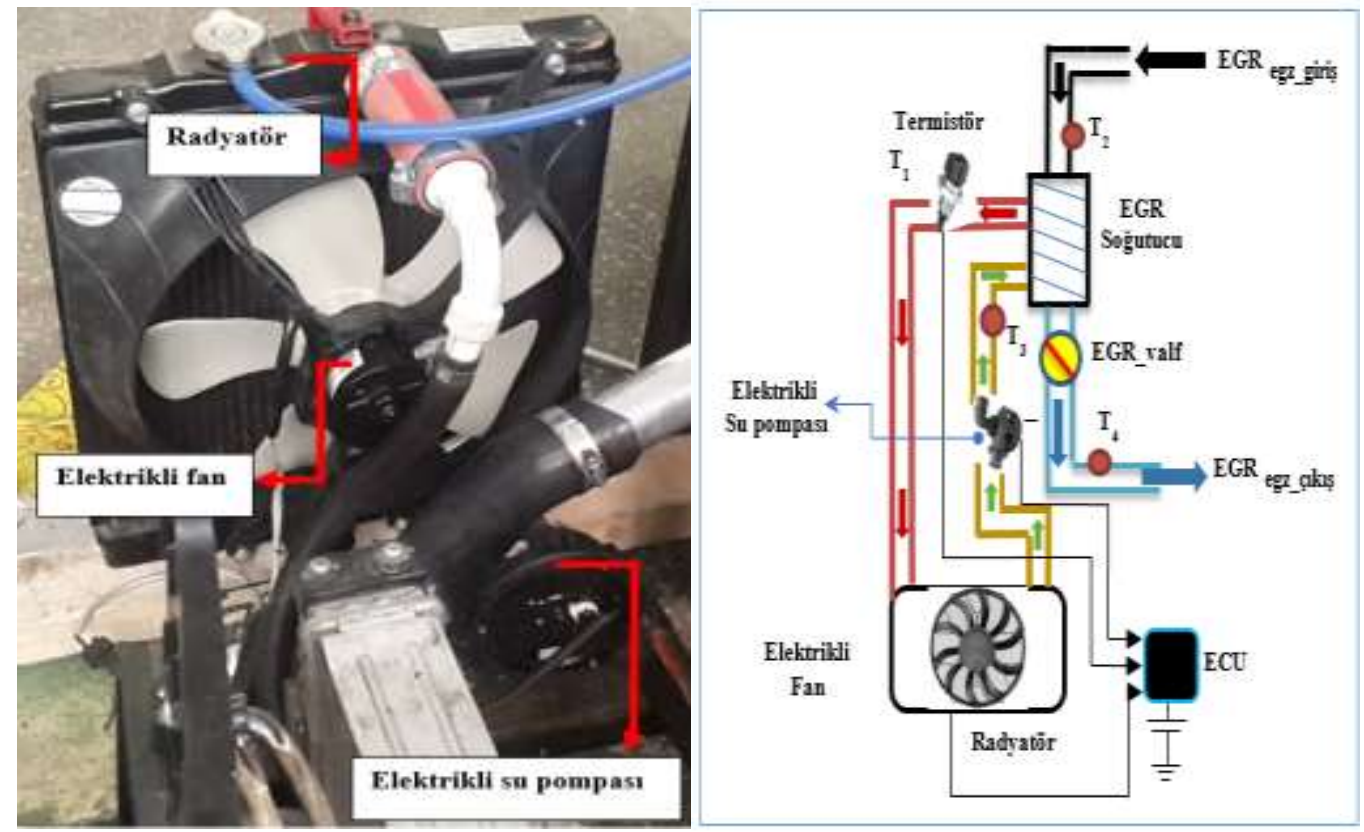

Şekil 4. Harici elektronik kontrollü EGR Soğutma sistemi ve şematik görünümü

Tasarlanan EGR devresinde bulunan pompa ve fan gibi elektromekanik bileşenlerin denetlenmesi klasik PI kontrol yapısı ile gerçekleştirilmiştir. EGR soğutma sisteminde akışkan pompası ve fan için üretilen kontrol işaretleri kompakt formda aşağıdaki gibi tanımlanır.

$\left[N_{\text {pump }}, N_{\text {Cooling fan }}\right]=\left(K_{P} e+K_{I} \int e d t\right)+u_{0}\left(N_{\text {pump }, 0}, N_{\text {Cooling fan }, 0}\right)$

Burada $K_{P}$ ve $K_{I}$ sırasıyla oransal ve integral pozitif kazanç sabitleridir. $u_{0}$ İse kontrol edilen parametrelerin başlangıç giriş değerleridir. Bu çalışmada $K_{P}$ ve $K_{I}$ oransal ve integral optimal kazanç değerlerinin belirlenmesinde "Pattern search" optimizasyon algoritması kullanılmıştır. Bu algoritmada referans değerinin izlenme hatası amaç fonksiyonu olarak tanımlandı ve denetleyici parametrelerinin optimal değerleri için 100 tekrarlanma gerçekleştirildi. Deneyler motorun kararlı çalışma koşullarında 1rasıyla $1700 \mathrm{~d} / \mathrm{d}$ ve $2000 \mathrm{~d} / \mathrm{d}$ da yüklü $(60-70 \mathrm{Nm})$ ve yüksüz $(20-30 \mathrm{Nm})$ koşullarda yapılmıştır. 
Motorun tüm bu çalışma koşullarında EGR oranları \%5, \%10 ve \%15 olarak ayarlanmıştır. Her devir için \%EGR oranları ve EGR soğutucu akışkan çıkış sıcaklıkları dikkate alınarak deneyler gerçekleştirilmiştir. Elektronik kontrollü EGR soğutma sisteminde soğutucu akışkan $\left(\mathrm{H}_{2} \mathrm{O}\right)$ çıkış sicaklıkları en düşük $40^{\circ} \mathrm{C}$, en yüksek $100^{\circ} \mathrm{C}$ arasında $10^{\circ} \mathrm{C}$ artımlarla EGR gazlarının sicaklık değişimlerini ve buna bağl1 olarak $\mathrm{NO}_{\mathrm{x}}$ ve $\mathrm{BSFC}$ değerleri analiz edilmiştir. Tablo 3 'de harici elektronik kontrollü EGR soğutma sistemi deney koşulları verilmiş̧ir.

Tablo 3. Harici elektronik kontrollü EGR soğutma sistemi deney koşulları

\begin{tabular}{|c|l|l|l|l|}
\hline $\begin{array}{c}\text { Motor } \\
\text { devri } \\
(\mathrm{d} / \mathrm{d})\end{array}$ & \multicolumn{1}{|c|}{$\begin{array}{c}\text { Yüklü/yüksüz koşullar } \\
(\mathrm{Nm})\end{array}$} & $\begin{array}{c}\text { EGR Oranı } \\
(\%)\end{array}$ & $\begin{array}{c}\text { EGR Su ç1kış } \\
\left({ }^{\circ} \mathrm{C}\right)\end{array}$ & $\begin{array}{c}\text { EGR Egzoz çık1ş } \\
\left({ }^{\circ} \mathrm{C}\right)\end{array}$ \\
\hline $1700 \pm 50$ & $\begin{array}{l}20 \pm 2 \text { (Yüksüz durum) } \\
60 \pm 2 \text { (Yüklü durum) }\end{array}$ & $\% 5-10-15 \pm 1$ & $40-50-60-70-80-90-100$ & $75-90-110 \pm 5$ \\
\hline $2000 \pm 50$ & $\begin{array}{l}30 \pm 2 \text { (Yüksüz durum) } \\
70 \pm 2 \text { (Yüklü durum) }\end{array}$ & $\% 5-10-15 \pm 1$ & $40-50-60-70-80-90-100$ & $75-90-110 \pm 5$ \\
\hline
\end{tabular}

\section{Bulgular ve Tartışma}

Yapılan deneysel çalışmada; kararlı durum ve belirtilen yük şartlarında alınan $\mathrm{NO}_{\mathrm{x}}$ ve $\mathrm{BSFC}$ değerleri, $1700 \mathrm{~d} / \mathrm{d}$ ve $2000 \mathrm{~d} / \mathrm{d}$ için analiz edilmiştir. Analizler surasında dizel motoru ile Tablo 2'de belirtilen şartlar dikkate alınarak deneyler gerçekleştirilmiş̧ir. Egzoz gazlarının içeriğindeki $\mathrm{H}_{2} \mathrm{O}$ ve $\mathrm{CO}_{2}$ 'nin silindire yönlendirilmesi silindir içerisinde seyreltme, kimyasal, termal etkilerinin yanında ateşleme gecikmesine de neden olmaktadır. Yanma odası içerisinde oksijen konsantrasyonunda ki azalma silindir içi yanma sıcaklığında bir düşmeye sebep olmaktadır. $\mathrm{NO}_{\mathrm{x}}$ emisyonlarındaki değişim silindir içi sıcaklığa bağlı olarak değiştiklerinden, $\mathrm{NO}_{\mathrm{x}}$ emisyonu sıcaklığın bir fonksiyonudur. Ayrıca yüksek motor devirlerinde, yakıt ve havanın daha iyi karışması nedeniyle yanma süreci gelişir. Yanma sürecindeki bu iyileşme püskürtülen yakıtın buharlaşmasını daha da kolaylaştırır.

Yapılan deneysel çalışmada EGR gazlarının EGR soğutucudan çıkış sıcaklıklarını $75^{\circ} \mathrm{C}-* 90^{\circ} \mathrm{C}$ (*klasik soğutma sistem koşulları) ve $110^{\circ} \mathrm{C}$ 'de kontrol edebilen ve klasik PI kontrol yapısına sahip elektronik denetleyici ile EGR gazlarının soğutucudan çıkış sıcaklıklarını belirtilen sıcaklıklarda tutarak her bir sıcaklık bölgesi için $\mathrm{NO}_{\mathrm{x}}$ ve BSFC verileri alınmıştır. Silindir içerisine alınan EGR gaz sıcaklıklarının artması, emme dolgusu sıcaklığını artıracağından $\mathrm{NO}_{\mathrm{x}}$ emisyonlarında artma gözlenecektir. Klasik EGR soğutma sistemine sahip motorlarda, kararlı durum çalışma koşullarında EGR gazları motor ana soğutma sistemi sayesinde EGR soğutucudan yaklaşık $90^{\circ} \mathrm{C}$ 'de emme manifolduna yönlendirilmektedir. Motor devrine, yüküne ve EGR oranına bağlı olarak sıcaklık sınır koşulları minumum $75^{\circ} \mathrm{C}$ ile maksimum $110^{\circ} \mathrm{C}$ olarak şekilde bu değerler referans alınmıştır.

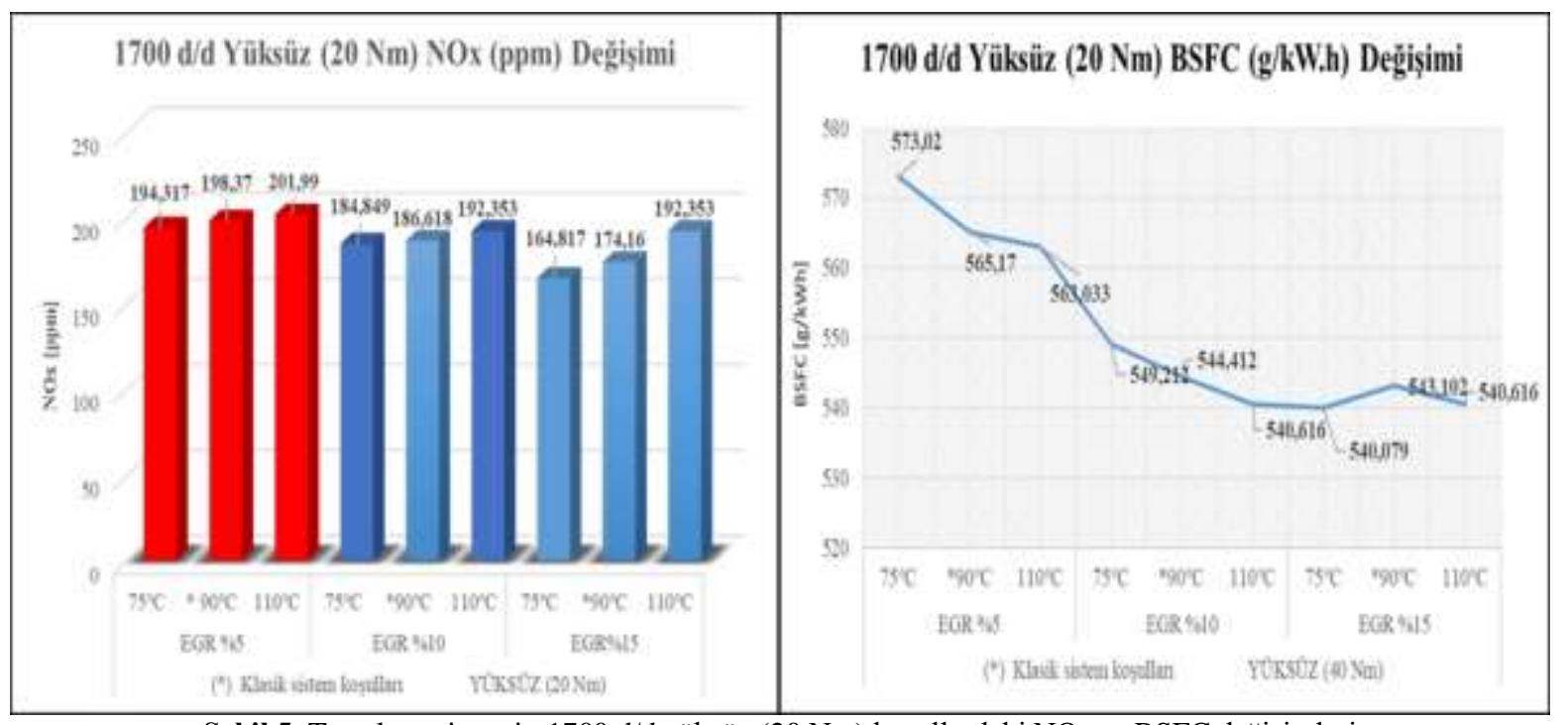

Şekil 5. Tasarlana sistemin $1700 \mathrm{~d} / \mathrm{d}$ yüksüz (20 Nm) koşullardaki $\mathrm{NO}_{\mathrm{x}}$ ve $\mathrm{BSFC}$ değişimleri 
Şekil 5'de 1700 d/d da yüksüz koşullardaki $\mathrm{NO}_{x}$ ve BSFC değişimleri görülmektedir. Şekil dikkatle incelendiğinde tüm EGR oranlarında belirtilen sınır sıcaklık koşulları, $90^{\circ} \mathrm{C}$ çıkış sıcaklığı olan klasik sistemdeki veriler ile kıyaslanmıştır. EGR oranının artırılması $\mathrm{NO}_{\mathrm{x}}$ emisyonlarını düşürecektir. Ancak sınır sıcaklık değerleri olan $75^{\circ} \mathrm{C}$ ve $110^{\circ} \mathrm{C}$ deki $\mathrm{NO}_{x}$ değişimleri BSFC ile birlikte ele alındığında $\% 15$ EGR oranında ve $75^{\circ} \mathrm{C}$ sıcaklık koşullarında klasik sistem sıcaklığına $\left(90^{\circ} \mathrm{C}\right)$ göre $\mathrm{NO}_{\mathrm{x}}$ ' da \%5,36 BSFC'de ise \%0,55 oranında bir iyileşme sağladığ görülmüştür.

Tasarlanan sistemle benzer karşılaştırma Şekil 6'da görüldügü üzere $1700 \mathrm{~d} / \mathrm{d}$ da yüklü koşullar için incelendiğinde klasik sisteme göre $\% 15$ EGR ve $75^{\circ} \mathrm{C}$ 'de $\% 20.76$ oranında $\mathrm{NO}_{\mathrm{x}}$ emisyonlarında azalma olurken BSFC'de \%4 (12.48 g/kWh) düşüş gözlenmiştir.

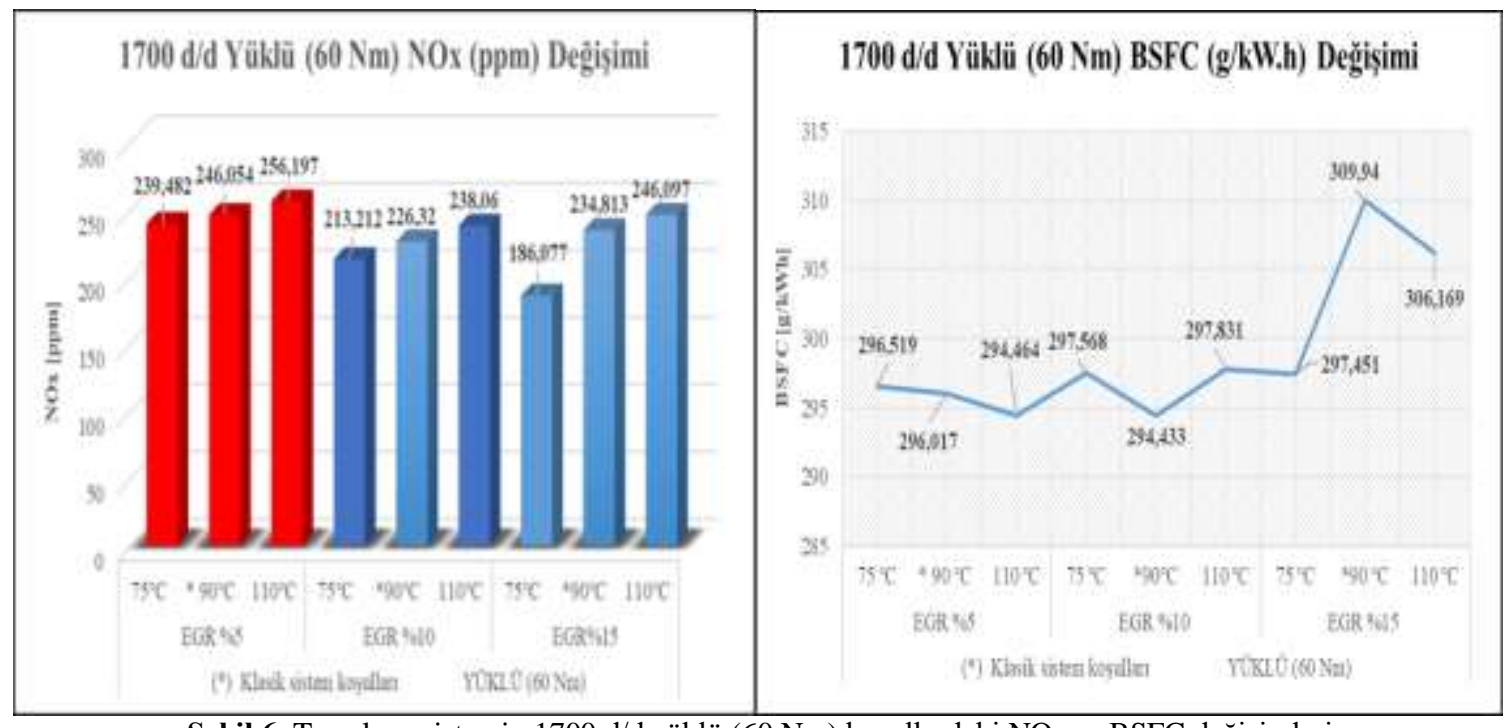

Şekil 6. Tasarlana sistemin $1700 \mathrm{~d} / \mathrm{d}$ yüklü $(60 \mathrm{Nm})$ koşullardaki $\mathrm{NO}_{\mathrm{x}}$ ve BSFC değişimleri

Dizel motor devri yükteki artışa karşılık daha verimli olmasının nedeni, silindirdeki azami havayı güç üretmek için kullanabilmesidir. BSFC, içten yanmalı bir motorun tüketmiş olduğu yakıta karşılık krank milinde üretmiş olduğu gücün verimini ifade eder ve yük arttığında en aza indirir. Motor devrinin artması hacimsel verimin iyileşmesine ve BSFC tüketiminde bir azalmaya sebep olur. Şekil 7'de $2000 \mathrm{~d} / \mathrm{d}$, yüksüz, \%5, \%10 ve \%15 EGR oranlarında yapılan deneysel sonuçların, $\mathrm{NO}_{\mathrm{x}}$ ve $\mathrm{BSFC}$ değişimleri görülmektedir. Grafikler incelendiğinde; klasik sisteme göre $75^{\circ} \mathrm{C}$ ve $\% 15$ EGR oranı optimum sıcaklık ve EGR oranıdır. Çünkü bu sıcaklık ve EGR koşullarında $\mathrm{NO}_{x}{ }^{\prime}$ da \%5.44 azalma meydana gelirken BSFC'de \%0.48 oranında düşük bir artışa sebep olmuştur.

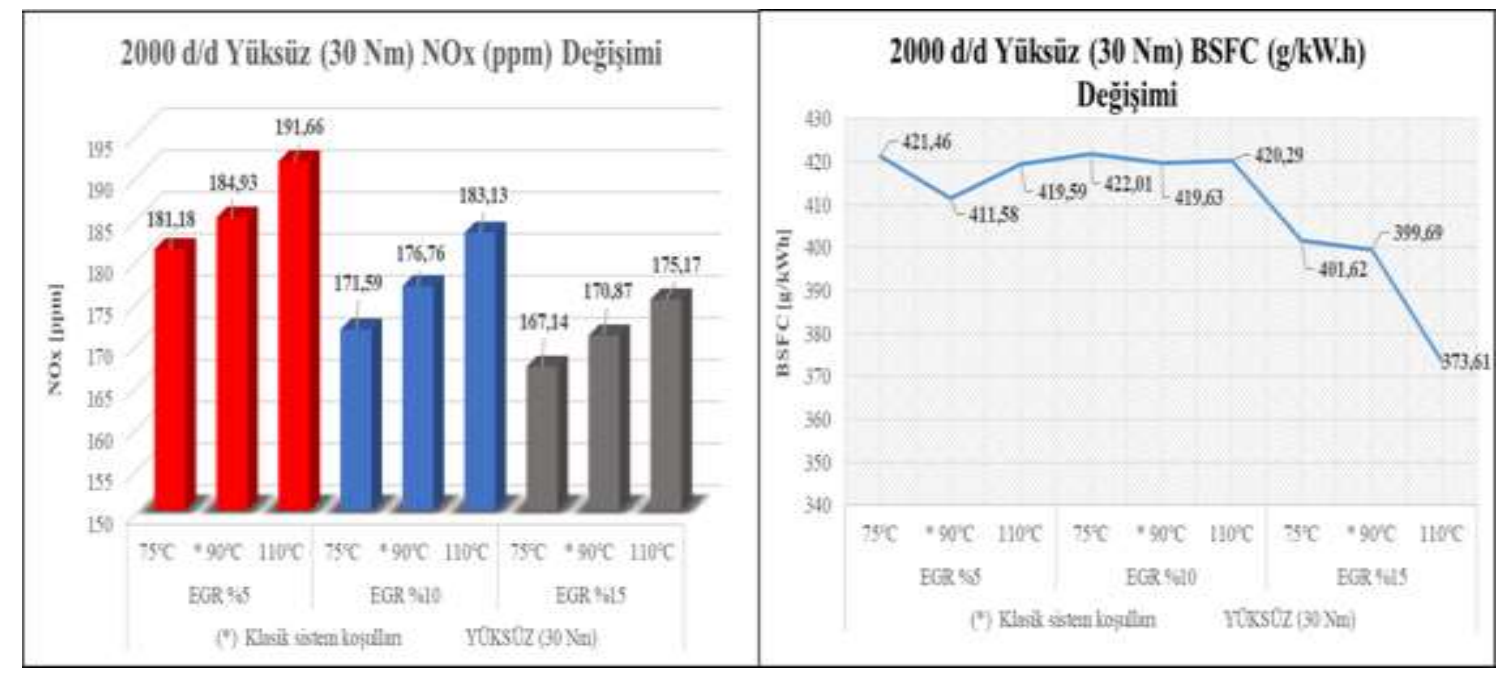

Şekil 7. Tasarlanan sistemin $2000 \mathrm{~d} / \mathrm{d}$ yüksüz $\left(30 \mathrm{Nm}\right.$ ) koşullardaki $\mathrm{NO}_{\mathrm{x}}$ ve $\mathrm{BSFC}$ değişimleri 
BSFC, EGR ile çalışan motorlarda EGR'siz olandan daha düşüktür. Bununla birlikte, motor yükü azaldıkça, EGR ile EGR'siz çalışma arasında BSFC açısından bir fark yoktur. Motor yükü en yüksek seviyede olduğunda, aşırı yakıt enjeksiyonu nedeniyle, EGR'li motorlarda hava yakıt-oranı değişir ve böylece BSFC artar [10]. Bu durum Şekil 8'de belirgin olarak görülmektedir. Öte yandan Şekil 8'deki grafikler incelendiğinde klasik sisteme göre etkin $\mathrm{NO}_{\mathrm{x}}$ düşüşleri $75^{\circ} \mathrm{C}$ sicaklıkta artan $\% 15$ 'lik EGR oranında \%8.96 $\mathrm{NO}_{\mathrm{x}}$ ve $\mathrm{BSFC}$ 'de $\% 1.96$ oranında eş zamanlı azalmaya sebep olduğu görülmüştür.

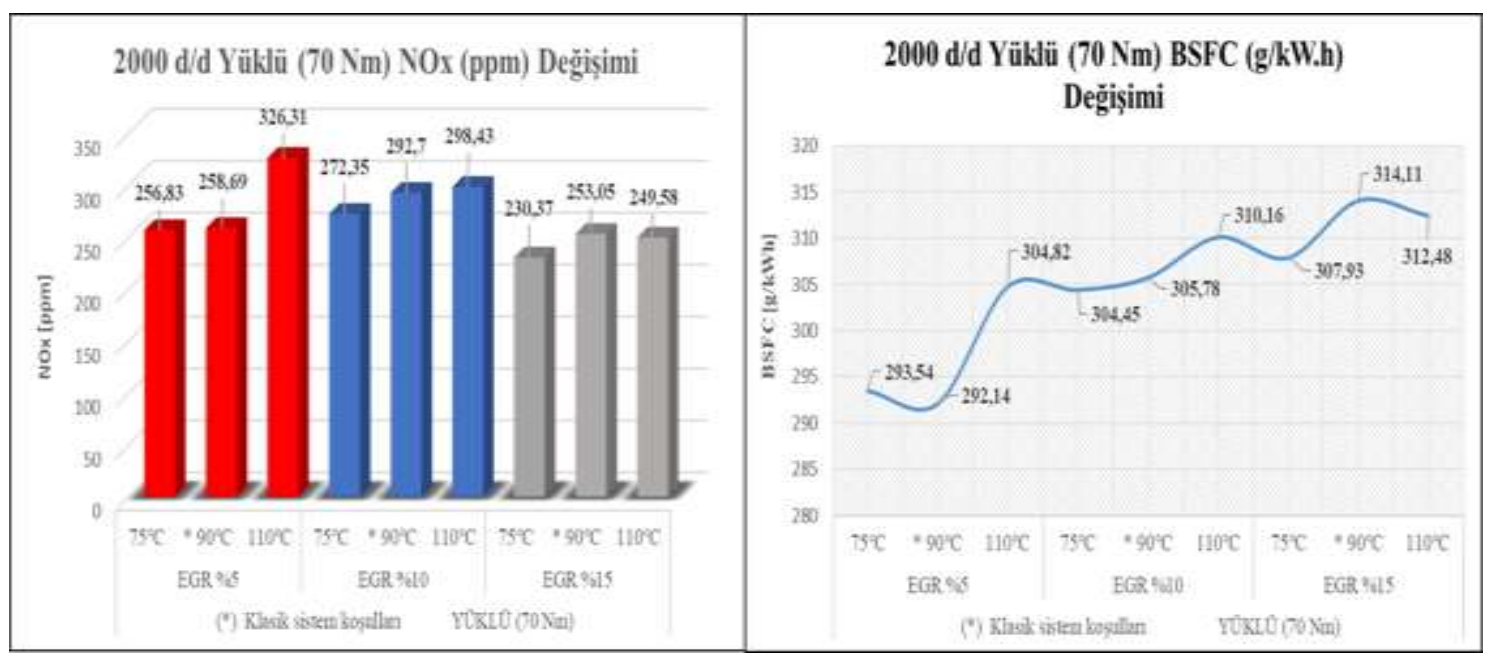

Şekil 8. Tasarlanan sistemin 2000 d/d yüklü $\left(70 \mathrm{Nm}\right.$ ) koşullardaki $\mathrm{NO}_{\mathrm{x}}$ ve $\mathrm{BSFC}$ değişimleri

\section{Sonuç ve Öneriler}

Tasarlanan kontrollü EGR soğutma sistemi ile klasik EGR soğutma sistemi belirtilen sıcaklıklarda, EGR oranlarında ve yük koşullarında karşılaştırılması yapılmıştır. Sonuçlar tasarlanan sistemin $1700 \mathrm{~d} / \mathrm{d}$ yüksüz koşullarda $\mathrm{NO}_{\mathrm{x}}$ 'da \%5.36 (9.34 ppm) BSFC'de ise \%0.55 (3.02 g/kWh) oranında azalmaya sebep olmuştur. Ayrıca $1700 \mathrm{~d} / \mathrm{d}$ yüklü koşullarda, $\% 15 \mathrm{EGR}$ ve $75^{\circ} \mathrm{C}$ 'de $\% 20.76$ oranında (48.73 ppm) $\mathrm{NO}_{\mathrm{x}}$ emisyonlarında azalma olurken BSFC'de \%4 (12.48 g/kWh) düşüş gözlenmiştir. Deneyler 2000 d/d'da aynı çalışma şartlarında tekrarlanmış olup yüksüz koşullarda $75^{\circ} \mathrm{C}$ ve $\% 15$ EGR oranında $\mathrm{NO}_{\mathrm{x}}$ ' da $\% 5.44(3.73 \mathrm{ppm})$ azalma görülürken BSFC' de \%0.48 (1.93 g/kWh) oranında bir artışa sebep olmuştur. $2000 \mathrm{~d} / \mathrm{d}$ yüklü çalışma koşullarında ise \%8.96 (22.68 ppm) $\mathrm{NO}_{\mathrm{x}}$ ve BSFC'de \%1.96 (6.18 g/kWh) oranında eş zamanlı azalmaya sebep olduğu görülmüştür. Soğutulmuş EGR uygulaması ile gelişmiş bir 1S1 yönetim sisteminin birleşimi öngörülen şartlara bağlı kalarak sıcaklıkları düzenleme yeteneğine sahiptir, bu nedenle minimum emisyon çıktıları ile optimum motor performansı için uygun bir seviyede çıkış sıcaklıklarını koruma amaçlı bir kontrol problemi bulunmaktadır. Tasarlanan sistem sayesinde, belirtilen, yük, devir, EGR oranlarında ve kararlı durum çalışma koşullarında EGR gaz sıcaklıklarının $\mathrm{NO}_{\mathrm{x}}$ ve BSFC değişimlerinde önemli bir etkiye sahip olduğu gözlenmiştir.

\section{Teşekkür}

Yapılan bu çalışma Atatürk Üniversitesi Bilimsel Araştırma Projeleri Koordinasyon birimince desteklenmiştir (Proje Numarası: 2015/362).

\section{Yazarların Katkısı}

Tüm yazarlar makalenin hazırlanmasında ve düzenlenmesinde eşit oranlarda katkıda bulunmuştur.

\section{Çıkar Çatışması Beyanı}

Yazarlar arasında herhangi bir çıkar çatışması bulunmamaktadır. 


\section{Araştırma ve Yayın Etiği Beyanı}

Yapılan çalışmada araştırma ve yayın etiğine uyulmuştur.

\section{Kaynaklar}

[1] Reşitoğlu İ.A., Altinişik K., Keskin A. 2015. The pollutant emissions from diesel-engine vehicles and exhaust aftertreatment systems. Clean Technologies and Environmental Policy, 17 (1): 1527.

[2] Jung H., Choi S. 2016. Model based burnt gas fraction controller design of diesel engine with VGT/Dual loop EGR system. International Journal of Automotive Technology, 17 (4): 555-566.

[3] Levendis Y.A., Pavlatos I., Abrams R.F. 1994. Control of Diesel Soot, Hydrocarbon and NOx Emissions with a Particulate Trap and EGR. SAE International, International Congress and Exposition, 28 February- 3 March, Michigan.

[4] Yamada T., Ikeya N., Kondoh N. 1998. New EGR system for heavy duty diesel engines. International Congress and Exposition, SAE transactions, 23-26 February, Michigan, pp: 10561064.

[5] Zheng M., Reader G.T., Hawley J.G. 2004. Diesel engine exhaust gas recirculation-a review on advanced and novel concepts. Energy Conversion and Management, 45 (6): 883-900.

[6] Arcaklioğlu E., Çelıkten İ. 2005. A diesel engine's performance and exhaust emissions. Applied energy, 80 (1): 11-22.

[7] Egnell R. 2000. The Influence of EGR on Heat Release Rate and NO Formation in a DI Diesel Engine. SAE International, International Spring Fuels and Lubricants Meeting and Exposition, 19-22 June, Paris.

[8] Abd-Alla G.H. 2002 Using exhaust gas recirculation in internal combustion engines: a review. Energy Conversion and Management, 43 (8): 1027-1042.

[9] Ladommatos N., Abdelhalim S., Zhao H. 2000. The effects of exhaust gas recirculation on diesel combustion and emissions. International Journal of Engine Research, 1 (1): 107-126.

[10] Agarwal D., Singh S.K., Agarwal A.K. 2011. Effect of Exhaust Gas Recirculation (EGR) on performance, emissions, deposits and durability of a constant speed compression ignition engine. Applied Energy, 88 (8): 2900-2907.

[11] Kakoi Y., Tsutsui Y., Ono N., Umezawa K., Kondo N. 1998. Emission Reduction Technologies Applied to High-Speed Direct Injection Diesel Engine. SAE International, International Congress and Exposition, 23-26 February, Michigan.

[12] Ishiki K., Oshida S., Takiguchi M., Urabe M. 2000. A study of abnormal wear in power cylinder of diesel engine with EGR-wear mechanism of soot contaminated in lubricating oil, SAE Technical Paper, SAE World Congress 6-9 March, Michigan.

[13] Schäfer F., Van Basshuysen R. 2013. Reduced emissions and fuel consumption in automobile engines, Springer Science and Business Media.

[14] Hountalas D.T., Mavropoulos G.C., Binder K.B. 2008. Effect of exhaust gas recirculation (EGR) temperature for various EGR rates on heavy duty DI diesel engine performance and emissions. Energy, 33 (2): 272-283.

[15] Langridge S., Fessler H. 2002. Strategies for High EGR Rates in a Diesel Engine. SAE International, SAE World Congress, 4-7 March, Michigan.

[16] Satoh K., Zhang L., Hatanaka H., Takatsuki T., Yokota K. 1997. Relationship between $\mathrm{NO}_{\mathrm{x}}$ and SM emissions from DI diesel engine with EGR. JSAE Review, 18 (4): 369-375.

[17] Shirawaka T., Miura M., Itoyama H., Aiyoshizawa E., Kimura S. 2001. Study of Model-based Cooperative Control of EGR and VGT for a Low-temperature, Premixed Combustion Diesel Engine. SAE International, Spring Fuels and Lubricants Meeting and Exhibition, 4-7 March, Florida.

[18] Vivek A., Sayali J., Tejas P., Mosim A. 2017. A Review Study of the effect of Exhaust Gas Recirculation (EGR) on performance and emission characteristics of diesel engine in National Conference "MOMENTUM-17", 14-15 February, International Journal of Research in Advent Technology (IJRAT) Special Issue, India. 
[19] Chalgren R.D., Parker G.G., Arici O., Johnson J.H. 2002. A Controlled EGR Cooling System for Heavy Duty Diesel Applications Using the Vehicle Engine Cooling System Simulation. SAE International, SAE World Congress 4-7 March, Michigan.

[20] Asad U., Zheng M. 2014. Exhaust gas recirculation for advanced diesel combustion cycles. Applied Energy, 123: 242-252.

[21] De Serio D., De Oliveira A., Sodré J.R. 2017. Effects of EGR rate on performance and emissions of a diesel power generator fueled by B7. Journal of the Brazilian Society of Mechanical Sciences and Engineering, 39 (6): 1919-1927.

[22] Sutela C., Collings N., Hands T. 2000. Real Time CO2 Measurement to Determine Transient Intake Gas Composition under EGR Conditions. International Fall Fuels and Lubricants Meeting and Exposition, 16-19 October, Maryland.

[23] Desantes J.M., Galindo J., Guardiola J., Dolz V. 2010. Air mass flow estimation in turbocharged diesel engines from in-cylinder pressure measurement. Experimental Thermal and Fluid Science, 34 (1): $37-47$.

[24] Dangar H., Rathod G.P. 2013. Combine effect of exhaust gas recirculation (EGR) and varying inlet air pressure on performance and emission of diesel engine. SAE International, IOSR Journal of Mechanical and Civil Engineering (IOSR-JMCE), 6 (5): 26-23.

[25] Hegarty K., Dickinson P., Cieslar D., Collings N. 2013. Fast O2 Measurement using Modified UEGO Sensors in the Intake and Exhaust of a Diesel Engine. SAE International.

[26] Choi K.W., Kim K.B., Lee K.H. 2009. Effect of New Cooling System in a Diesel Engine on Engine Performance and Emission Characteristics. SAE International Journal of Engines, 2 (1): 77-82.

[27] Haghighat A.K., Roumi S., Madani N., Bahmanpour D., Olsen M.G. 2018. An intelligent cooling system and control model for improved engine thermal management. Applied Thermal Engineering, 128: 253-263. 